\title{
EXPANSÃO E INVESTIMENTO NA PÓS-GRADUAÇÃO EM DIREITO NO BRASIL - 1995/2005
}

\author{
Aldacy Rachid Coutinho*
}

RESUMO: O artigo procura analisar a expansão e o investimento na Pós-graduação em Direito no Brasil no período de 1995 a 2005. A autora demonstra mediante dados obtidos junto à CAPES e ao CNPq que a expansão, sob controle, da área do Direito, foi mais intensa que a de outras áreas, ao passo que o investimento em pesquisa na pós-graduação não tenha acompanhado o mesmo ritmo.

Ensino não é mercadoria. Na economia capitalista de mercado não-monopolista, a pretensa "coisificação" da educação superior em uma sociedade de massa que se disfarça em sociedade de conhecimento projeta todo discurso para o espaço mercantilista da oferta/ demanda pautado pela lógica dos custos.

Vivencia-se uma crise de identidade, ${ }^{1}$ perceptível e acentuada pelas dificuldades dos incluídos, pressão e crítica dos não-incluídos e desconhecimento dos não-incluíveis no Sistema Nacional de Pós-graduação -

* Advogada. Procuradora do Estado do Paraná. Mestre e Doutora em Direito. Professora de Direito do Trabalho na Universidade Federal do Paraná. Coordenadora eleita do Programa de Pós-graduação em Direito (Mestrado, Doutorado e Pós-doutorado) da Universidade Federal do Paraná no biênio 2004/2006.

${ }^{1}$ Acentuada pelas discussões em torno dos mestrados profissionalizantes, oferta de cursos em convênio com instituições estrangeiras no Brasil e abertura de LLMs.
SNPG, sob pressão de um crescimento desmesurado de Faculdades de Direito $^{2}$ e da necessidade de qualificação - erroneamente confundida com a titulação - dos recursos humanos disponíveis.

Todavia, adotou-se na Área do Direito, por seu Comitê composto de professores doutores pesquisadores e consultores ad hoc que colaboram temporária, voluntária e graciosamente como membros, uma política de expansão criteriosa, "fortemente focada na qualidade da pesquisa, e muito mais centrada em uma desconcentração da pós-graduação dos grandes centros, do que na massificação do ensino pós-graduado em Direito". ${ }^{3}$

\footnotetext{
${ }^{2}$ Estamos perto de 900 Faculdades de Direito.

${ }^{3}$ Documento de Área, Área de Direito, 2001-2003, setembro de 2004, Representante da Área do Direito junto a CAPES, Professor Doutor Fernando Facury Scaff.
} 
E la nave và. Respiramos agora os ares do terceiro Plano Nacional de Pós-graduação elaborado para o período de 2005-2010. $\mathrm{E}$, até o momento, ainda permanece tudo sob controle, apesar de algumas decisões recentes emanadas do Comitê Técnico Científico indicar certa rota de colisão com os pareceres emanados do Comitê da Área do Direito, o qual, como é primário, encontrase, por conhecimento próprio, mais perto das questões que envolvem a própria Área e, assim, faz análises mais criteriosas das situações fáticas peculiares, o que pode ser observado inclusive pela fundamentação das decisões dos dois órgãos.

Expansão, sim. Também crescimento, é claro. Porém, desde que respeitado o inafastável comprometimento com a qualidade, mantido a "qualquer custo" e devidamente acompanhado de investimento. Reputa-se como pouco representativa a expansão da Área do Direito em face das demandas apresentadas e supostamente excessivamente rígidas as análises dos que pretendem o ingresso no Sistema Nacional de Pós-graduação, mas os números e a comparação com outras áreas demonstram a falsidade da imputação, além do que o crescimento quantitativo dos cursos não ocorreu no mesmo nível dos recursos disponíveis.

\section{INTEGRANDO O SNPG}

A pós-graduação se perfaz com a formação e o aperfeiçoamento de docentes e pesquisadores, no intercâmbio de conhecimento entre as distintas ciências e campos, por meio da produção intelectual.
O Parecer Sucupira, ${ }^{4}$ conhecido pelo nome do relator na Câmara de Ensino Superior (C.E.Su) do então Conselho Federal de Educação, Prof. Dr. Newton Sucupira, proferido em 3 de dezembro de 1965, dá conta de uma longa trajetória da construção da pós-graduação no Brasil. Ao precisar conceitos visando à implantação e ao desenvolvimento do regime de cursos de pós-graduação, acabou por fixar os pilares e os marcos das políticas públicas que dimensionam a atuação do Estado até os nossos dias. Eis, diga-se desde logo, um dos poucos setores em que o país tem - e executa-políticas públicas com continuidade, inabalável seriedade e máximos resultados, notáveis e reconhecidos.

A pós-graduação se revelou como a "conseqüência natural do extraordinário progresso do saber", inviável enquanto exclusividade do espaço da graduação voltada que era - e é - à preparação de profissionais. Também a dos cientistas projetou-se, então, para um momento seqüencial: a formação de pesquisadores. Por conseguinte, esclarece o parecerista: a pós-graduação sensu stricto se caracteriza fundamentalmente pela (a) natureza acadêmica e de pesquisa, permanecendo para o lato sensu a especialização práticoprofissional; (b) confere grau acadêmico e não um mero certificado, tal qual ocorre nas especializações; (c) possui uma sistemática, formando estrato essencial e superior na hierarquia dos cursos dentro do complexo universitário, escalonada em dois níveis distintos ou ciclos, o Mestrado e o

${ }^{4}$ Reforma universitária e consolidação do regulamento da pós-graduação. Parecer 977, de 03 de dezembro de 1965. InfoCapes - Boletim Informativo da CAPES. Brasília, out./dez.99, v.7, n.4, p. 37-51. 
Doutorado, que apesar de hierarquizados são relativamente autônomos, porquanto um não é necessariamente a condição indispensável ao ingresso no curso seguinte. No ápice, o Curso de Doutorado. Imperioso notar, todavia, que a preparação para o exercício do magistério superior é realizado tanto em cursos de Mestrado quanto de Doutorado. ${ }^{5}$

Dessa forma, desde 1965 resta estabelecido no Brasil que, em uma área de concentração e dentro das linhas de pesquisa, o pósgraduando terá garantida a sua formação optando por matérias, em disciplinas básicas ou fundamentais, complementadas por específicas e de domínio conexo, expressos em créditos, com avaliação para aproveitamento em cursos de duração limitada, com um mínimo de carga horária. Garante-se ao pósgraduando, a par do conhecimento teórico que embasa a pesquisa por meio de aulas e seminários ministrados, igualmente um campo para o desenvolvimento da pesquisa individual e em grupo.

Nesse trilhar, a Fundação Coordenação de Aperfeiçoamento de Pessoal Superior CAPES $^{6}$ tem a função de credenciar e avaliar para fins de manutenção do credenciamento

\footnotetext{
${ }^{5}$ Art. 66. Lei n. ${ }^{\circ}$ 9.394, de 20 de dezembro de 1996. LDB - Lei de Diretrizes e Bases da Educação.

${ }^{6}$ A CAPES foi criada pelo Decreto n. ${ }^{\circ} 29.741$, de 11 de julho de 1951, tendo como objetivo "assegurar a existência de pessoal especializado em quantidade e qualidade suficientes para atender às necessidades dos empreendimentos públicos e privados que visam ao desenvolvimento do país". Em 1981, pelo Decreto n. ${ }^{\circ}$ 86.791, a CAPES é reconhecida como órgão responsável pela elaboração do Plano Nacional de Pós-graduação stricto sensu e agência executiva do então Ministério da Educação e Cultura, tendo a função de elaborar, avaliar, acompanhar e coordenar as atividades da pós-graduação. Posteriormente foi tranformada em Fundação, pela Lei n. ${ }^{\circ} 8.405$, de 9 de janeiro de 1992.
}

os Cursos de Pós-graduação, atuando ademais como agência pública de fomento da pesquisa, a partir da edição de políticas públicas de pós-graduação.

Por certo que a Constituição da República de $1988^{7}$ assegura às Universidades ${ }^{8}$ a autonomia como princípio, porém tal não significa estar à margem dos marcos regulatórios ${ }^{9}$ estabelecidos no legítimo interesse de toda a sociedade em prol de um padrão mínimo de excelência. Autonomia, como é primário, não é aval à irrestrita liberdade de atuação e, portanto, vem delimitada pelo marco regulatório dentro do qual se pode até ter a possibilidade de fazer incidir a conveniência e oportunidade.

Não se coadune com a autonomia o arbítrio, com o qual se vê corriqueiramente confundido. Daí que a abertura e o funcionamento de cursos de pós-graduação stricto sensu dependem da prévia análise de um projeto que, obtendo parecer favorável ou não no Comitê da Área do Direito, deve ainda ser aprovado pelo Comitê Técnico Científico - CTC na CAPES para, posteriormente, ser homologado pelo Conselho Nacional da Educação - CNE, vinculado ao Ministério da Educação.

\footnotetext{
7 “Art. 207. As universidades gozam de autonomia didático-científica, administrativa e de gestão financeira e patrimonial, e obedecerão ao princípio da indissociabilidade entre ensino, pesquisa e extensão." Constituição da República de 1988.

${ }^{8}$ Quanto à organização acadêmica, as instituições do Sistema Federal de Ensino são classificadas em universidades, centros federais de educação tecnológica e centros universitários, faculdades integradas e de tecnologia e faculdades e institutos e escolas superiores.

9 "Art. 209. O ensino é livre à iniciativa privada, atendidas as seguintes condições: I - cumprimento das normas gerais da educação; II - autorização e avaliação de qualidade pelo Poder Público.”
} 
O curso poderá iniciar suas atividades somente a partir da publicação da respectiva Portaria de reconhecimento no Diário Oficial da União. Dada a questão da autonomia assegurada como princípio constitucional exclusivamente às Universidades, excepcionalmente é garantida a estas iniciar as atividades após a aprovação interna corporis do Curso pretendido - em nível de Mestrado ou de Doutorado -, devendo o projeto, sem embargo, ser remetido para análise - e aprovação - dentro de exíguo prazo previamente estabelecido.

Para além do atendimento dos critérios gerais para oferta de cursos de pós-graduação (fixados pela Capes), as Áreas estabelecem, em face de algumas peculiaridades, outros critérios que devem igualmente ser atendidos, permitindo, dessa forma, ao mesmo tempo o controle da qualidade na expansão e o atendimento de especificidades.

As avaliações contínuas a que todos os Programas reconhecidos se submetem certificam os padrões de excelência nos estudos e pesquisa. Somente Programas que integrem o Sistema Nacional de Pósgraduação, pelo prévio reconhecimento, poderão emitir títulos com validade nacional, perdendo tal prerrogativa se na avaliação se comprovar a insuficiência de um padrão mínimo de qualidade. No aspecto temporal, o critério de fixação da validade do título é dado pela data de ingresso do pós-graduando no curso, em necessidade de preservação da aparência, boa-fé e segurança jurídicas, pelo que a saída de um programa do SNPG não impede de imediato a outorga do grau acadêmico, mas restringe a possibilidade àqueles que já integravam o corpo discente quando da avaliação negativa.

\section{POR UMA QUESTÃO DE AVALIAÇÃO}

Como a autorização e o reconhecimento dos cursos, assim também o credenciamento das instituições tem prazo limitado e a renovação periódica é procedida após regular processo de avaliação. ${ }^{10}$ A criação da sistemática de avaliação continuada pela CAPES está em vigência desde 1999.

O atual sistema de avaliação segue já para o terceiro período. A título de esclarecimento, até 1998 (1996-1998) a avaliação era bianual, sendo que desde 1996 a classificação deixa de ser procedida por letras (A, B, C, D e E), sendo parametrizada por meio dos números 1(um) a 7(sete). A primeira avaliação trienal ocorreu em relação aos anos 1998-19992000, a segunda 2001-2002-2003 e, agora, em 2006, encerra o terceiro ciclo iniciado em 2004.

A avaliação de todos os Programas de Pós-graduação no Brasil é procedida de forma continuada nos dois primeiros anos-calendário do triênio, que servirão de indicativos tanto para o planejamento e ações dos próprios Programas (com vistas a eventuais mudanças e ajustes procedidos para seu fortalecimento diante de pontos fracos apontados) quanto para a Comissão de Área que, no último ano do triênio, procederá à verificação do desempenho com base nos critérios previamente estabelecidos e publicizados, atribuindo-lhes uma nota. A avaliação é meramente declaratória - e não constitutiva - da situação verificada nos cursos.

\footnotetext{
${ }^{10}$ Art. 46. Lei n. ${ }^{\circ} 9.394$, de 20 de dezembro de 1996.
} Lei de Diretrizes e Bases da Educação Superior - LDB 
Em uma escala de conceitos de 1 (um) a 7 (sete), em sentido crescente de qualidade, o credenciamento e a manutenção no Sistema Nacional de Pós-graduação do Programa dependerão de nota mínima 3 (três), que lhe permitirá a emissão de um título com validade nacional. As notas 6 (seis) e 7 (sete) tão-somente serão atribuídas a Programas que contem com cursos de Mestrado e Doutorado, de sorte que o isolado Curso de Mestrado, ainda que de grandes méritos e excelência, terá nota máxima 5 (cinco).

$\mathrm{O}$ perfil de excelência expressa o atendimento das definições e peculiaridades estabelecidas em cada Área, após amplo debate com a comunidade acadêmica, servindo de parâmetro para revelar um padrão acadêmico de inserção internacional. Dentre os critérios estão (a) a participação e o intercâmbio de docentes estrangeiros no Programa ou a participação dos docentes do Programa em atividades no exterior; (b) a relevância científica de alcance internacional dos projetos de pesquisa desenvolvidos, em conformidade com a fundamentação teórica, a consistência metodológica, a originalidade do projeto e, especialmente, a importância para o desenvolvimento científico na área de conhecimento no que tange à inovação; (c) a qualidade dos veículos ou meios de divulgação, entendida como publicação em editoras de reconhecida expressão internacional, sendo levados em consideração os livros, capítulos de livros e artigos de periódicos; (d) o grau de difusão dos resultados obtidos com a pesquisa; (e) a participação discente, quer de estrangeiros no Programa, quer de nacionais em atividades de pesquisa no exterior, inclusive com o denominado "doutorado sanduíche"; ${ }^{11}$ (f) além da participação em eventos internacionais, comissões ou consultorias científicas no exterior, captação de financiamento para pesquisas, promoção de eventos científicos internacionais, intercâmbios e convênios de cooperação internacional ativos e que caracterizem reciprocidade entre as instituições.

O Comitê avaliador é composto por Professores Doutores indicados pela CAPES, ${ }^{12}$ sendo que nas três avaliações trienais um observador externo ao Comitê da Área do Direito, docente de uma instituição de renome internacional, bem como um representante discente, ${ }^{13}$ acompanharam os trabalhos, garantindo a necessária e democrática transparência.

Tendo por base algumas premissas, tais como a primazia da avaliação qualitativa sobre a quantitativa diante das peculiaridades da realidade na qual os Programas se inserem, a não permitir uma parificação mecânica ou numérica expressa em percentual, ou o atendimento das recomendações da área quanto à objetividade, somente os elementos trazidos pelos próprios Programas no aplicativo eletrônico disponibilizado pela CAPES (DataCapes) são levados em consideração quando da avaliação.

A avaliação é procedida a partir das informações prestadas pelos Programas

\footnotetext{
${ }^{11}$ Estágio de pesquisa e estudo durante o curso de Doutorado em Universidade estrangeira.

12 O Coordenador e Coordenador Adjunto, professores doutores, são designados pela CAPES, exercendo função (nem emprego, nem cargo) não remunerada, para um triênio.

${ }^{13}$ No Conselho Técnico Científico da CAPES tem assento um representante discente da Associação Nacional dos Pós-graduandos.
} 
mediante o preenchimento de um Relatório Anual DATACAPES, preenchido ${ }^{14}$ on line com a chancela da respectiva Pró-Reitoria de Pós-graduação de cada instituição, bem como diante de informações prestadas por meio do cadastro discente e banco nacional de teses e dissertações enviadas em PDF a serem futuramente disponiblizadas para acesso irrestrito ao público. Os critérios vinham elencados em 7 (sete) quesitos com distinta ponderação em pesos, cada qual composto de 5 (cinco) itens comuns a toda pós-graduação e até 2 (dois) definidos pela Área por conta de especificidades do Direito, com indicativos possíveis DEFICIENTE, FRACO, REGULAR, BOMEMUITO BOM. Para a avaliação trienal de 2006, a Ficha de Avaliação foi alterada, com a condensação em 5 (cinco) quesitos, permitindo assim a inclusão de novos critérios, tais como: inserção social, solidariedade e visibilidade ou transparência.

Os avaliadores, oriundos da comunidade científica, exercendo função pública não remunerada, ao avaliar os pares garantem um tratamento não tecnicista no manejo dos dados, preservando as especificidades de cada área.

Na Área do Direito, os critérios são amplamente debatidos pelos próprios Programas e na comunidade jurídica acadêmica em reuniões realizadas na CAPES e (ou) no âmbito do CONPEDI - Conselho Nacional de Pesquisa e Pós-graduação em

${ }^{14}$ Até 2006, preenchido off line e encaminhado por suas respectivas Pró-Reitorias de Pós-graduação à CAPES; atualmente o cadastro discente e envio de trabalhos de conclusão em pdf para o banco de teses e dissertações permanece aberto todo o ano.
Direito por seu Fórum de Coordenadores, de sorte a sempre garantir a sua divulgação prévia para implementação de ações no âmbito das respectivas coordenações de cursos, sanear dúvidas e permitir o aprimoramento do próprio processo de avaliação com eventuais ajustes.

\section{O primeiro quesito, Proposta do} Programa, não tem peso e é verificado a partir da análise da (1) sua coerência, consistência, abrangência e atualização das áreas de concentração, linhas de pesquisa e projetos em andamento, articulando meios e fins com as linhas de pesquisa e áreas de concentração, que demandam articulação em um eixo temático que as una organicamente e transcendam às temáticas dogmáticodisciplinares; (2) coerência, consistência e abrangência da estrutura curricular, com disciplinas reflexivas, ementas atuais e que não reproduzam conteúdo e (ou) guardem características de disciplinas de graduação e (ou) especialização, ministradas por docentes com produção aderente; (3) infra-estrutura para ensino, pesquisa e extensão, sustentada em instalações e equipamentos que assegurem a realização de objetivos da Proposta, acesso a internet, sistemas de informática, biblioteca, salas para professores, salas de trabalho e orientação de alunos, bem como auditório para conferências, inclusive adaptado às pessoas portadoras de deficiência.

O segundo quesito da avaliação, com peso 30, é o Corpo Docente, que sofre uma alteração no terceiro triênio com a edição da Portaria n. ${ }^{\circ}$ 68, de 03 de agosto de 2004, ao abandonar o enquadramento e classificação dos docentes em torno de um Núcleo de Referência Docente com seis níveis (NRD1 
a NRD6) ${ }^{15}$ para absorvê-los em 3 (três) distintas categorias, a saber: (a) docentes permanentes, necessariamente doutores, constituindo o núcleo principal de docentes do Programa e que desenvolvem atividades de ensino na pós-graduação e (ou) graduação, participam de projeto de pesquisa, orientam mestrandos ou doutorandos, devidamente credenciados a tal fim, tendo vínculo funcional com a instituição ou, excepcionalmente, em até $20 \%$ do total do corpo docente, os que (a.1) recebam bolsa de fixação de docentes, pesquisadores de agências federais ou estaduais de fomento; (a.2) estejam aposentados, mas tenham firmado termo de compromisso de participação; (a.3) tenham sido cedidos por convênio formal para atuarem como docentes; (b) docentes visitantes e, por último, os (c) docentes colaboradores que participam de forma sistemática do desenvolvimento de projetos de pesquisa ou atividades de ensino e (ou) orientação, possuindo ou não vínculo com a instituição. Até $20 \%$ do total de docentes permanentes poderão atuar em 2 (dois) distintos Programas de Pós-graduação em Direito, garantindose uma limitada flexibilidade antes não autorizada, porém sem deixar de atender às necessidades de fixação do docente no Programa, de modo a garantir o atendimento dos objetivos estabelecidos com a construção de um curso centrado em linhas de pesquisa,

${ }^{15}$ A consistência de um Programa era dada pelo NRD6, que não permitia a duplicação de professores atuando em distintos mestrados ou doutorados e que, com vínculo permanente (emprego privado ou cargo público), estavam em regime de trabalho de 40 (quarenta) horas, com pelo menos $30 \%$ do tempo destinado às atividades da pós-graduação, onde orientavam, ministravam aulas e pesquisavam. mas na hipótese, o resultado da pesquisa desenvolvida não poderá ser compartilhada entre as instituições. Os indicadores do Corpo Docente incentivando a contração mediante pagamento dos professores por regime de trabalho e não horas de tablado é elemento imprescindível na preservação de condições mínimas de trabalho que permitam o desenvolvimento de pesquisa.

Serão levados em consideração para o Corpo Docente a (1) formação com titulação, sendo a totalidade do corpo docente composta de professores doutores, diversificação na origem de formação para evitar endogenia, aprimoramento e experiência para evitar jovens doutores (30\%); (2) adequação da dimensão, composição e dedicação dos docentes permanentes para o desenvolvimento das atividades de ensino, pesquisa e orientação do programa, com um mínimo de 10 (dez) doutores, dos quais $80 \%$ com doutoramento em Direito no curso de mestrado e para o doutorado, um mínimo de 15 (quinze) doutores com pelo menos 12 doutores em Direito (20\%); (3) perfil, compatibilidade e integração do corpo docente permanente com a Proposta do Programa (especialidade e adequação em relação à proposta do programa), para evitar fragilidades ou dependência de membros externos de sorte a assegurar o atingimento dos objetivos e demandas do Programa, com a devida aderência (10\%); (4) atividade docente e distribuição da carga letiva entre docentes permanentes, havendo equilíbrio, no conjunto dos professores, com atribuição de carga horária nas respectivas disciplinas $(5 \%)$; (5) participação dos docentes nas atividades de ensino e pesquisa na graduação, com particular atenção à repercussão que este item 
pode ter na formação de futuros ingressantes da Pós-graduação, evitando, todavia, a exigência de uma demasiada participação dos docentes nas atividades da graduação (5\%); (6) participação dos docentes em pesquisa e desenvolvimento de projetos, devidamente registrados no $\mathrm{CNPq}$ e (7) dimensão do corpo docente permanente em relação ao corpo discente, tomando-se por padrão de excelência um razão de 6/1 (25\%).

O terceiro quesito, com peso 25 , diz respeito ao Corpo Discente, Teses e Dissertações e que explicitarão a análise de (1) orientações de teses e dissertações concluídas no período de avaliação em relação ao corpo docente permanente e à dimensão do corpo discente (15\%); (2) adequação e compatibilidade da relação orientador/ discente, analisadas separadamente o fluxo de ingresso de novos alunos e titulação no período, bem como número de orientados por professor, com critérios distintos para curso de mestrado e doutorado (10\%); (3) participação de discentes autores da pós-graduação e da graduação na produção científica do programa, com análise do número de artigos e número de alunos autores em relação à totalidade do corpo discentes (20\%); (4) qualidade das teses e dissertações e suas vinculações a publicações (20\%); (5) qualidade das teses e dissertações por demais indicadores (25\%); e (6) eficiência do Programa na formação de mestres e doutores, com tempo de formação de mestres e doutores e percentual de bolsistas da Capes e do CNPq titulados, considerando, de forma diferenciada, a situação de bolsistas e de não bolsistas, bem como alunos vinculados a projetos especiais aprovados pela Capes, como Minter (Mestrado Interinstitucional) e Dinter (Doutorado Interinstitucional) (10\%). Imperioso pontuar que os Projetos de Pesquisa pertencem ao Programa e devem ser desenvolvidos prioritariamente de forma não individual, em Núcleos ou Grupos de Pesquisa, sob coordenação de um professor doutor integrante do Corpo Docente, sendo devidamente formalizados na instituição, podendo ou não receber investimentos.

O quarto quesito, com peso $35 \%$, se refere à Produção Intelectual, observada pelas (1) publicações qualificadas do Programa por docente permanente (60\%); (2) distribuição de publicações qualificadas em relação ao corpo docente do Programa, sendo que a qualidade dos veículos ou meios de divulgação vem aferida pelo Qualis ${ }^{16}$ da Área de Direito (20\%); (3) outras produções consideradas relevantes, à exceção da artística por impertinente, sendo para o Direito prioritariamente a produção técnica, assim considerada como participação em seminários, conferências, palestras realizadas fora do próprio Programa e no exterior $(20 \%)$.

Por fim, último quesito, com peso definido como 10, a Inserção Social sendo assim considerada a (1) inserção e impacto regional e ou nacional do programa sob aspecto

${ }^{16}$ Ranking do impacto da publicação de anais, jornais, revistas e periódicos por autores discentes e docentes no ano, como veículos de divulgação da produção científica, a partir da circulação e do impacto (locais A, B e C), nacionais (A, B e C) e internacionais (A, B e C) - sendo que os últimos não se confundem com estrangeiros -, analisados, classificados e revistos anualmente por Comissão especialmente designada na CAPES, a partir da lista elaborada pela tabulação das informações prestadas pelos Programas no Relatório DATACAPES. O Qualis, assim, é instrumento de assessoramento para avaliação. 
educacional, social, cultural, tecnológico e econômico (50\%); (2) integração e cooperação com outros programas com vistas ao desenvolvimento da pesquisa e da pósgraduação, com participação em acordos de cooperação e intercâmbio sistemáticos (25\%) e (3) visibilidade ou transparência dada pelo programa à sua atuação, com manutenção de página da Web atualizada para divulgar dados internos, critério de seleção de alunos novos, financiamento e prestação de contas de recursos recebidos e garantia de amplo acesso a teses e dissertações nos termos da Portaria n. ${ }^{\circ}$ 13/2006- CAPES (25\%).

De forma específica, para a internacionalização de programas notas 6 e 7, com diferenciais de alta qualificação e desempenho, sendo (1) nível de qualificação, de produção e de desempenho equivalentes ao dos centros internacionais de excelência na formação de recursos humanos; (2) consolidação e forte liderança nacional do programa como formador de recursos humanos para a pesquisa e a pós-graduação, isto é, nucleação de grupos de pesquisa e de programas de pós-graduação; (3) inserção e impacto regional e (ou) nacional do programa, estimulando e premiando formas inovadoras na pesquisa e na formação de mestres e doutores, com recorte interdisciplinar, inclusive mediante estágios de pós-doutorado.

\section{UM OLHAR NA EXPANSÃO}

Nos últimos 10 anos (1996-2006) a expansão foi contínua e significativa, resultando uma ampliação da ordem de 222,22\% em relação ao número de Programas de Pós-graduação em Direito integrantes do
SNPG, mais expressiva para os Cursos de Doutorado, que contaram com um incremento de $425 \%$, do que dentre os Cursos de Mestrado, que ampliaram numericamente seus cursos em 222,22\%.

No espaço temporal seguido de 1995 a 2006 observa-se, inclusive, que o aumento no número de Programas de Pós-graduação em Direito é maior do que o próprio crescimento geral da Pós-graduação, pois enquanto a Área ampliou em $190 \%$ o número de programas, a pós-graduação se limitou a um crescimento de $94,88 \%$.

Em 2006, do total de Programas (2.388) no Brasil, a grande área de Ciências Sociais Aplicadas responde com 291 (12,18\%) e o Direito com 58 (2,42\%). Dentre os 3.572 cursos ofertados (M e D) no Brasil, 388 são da grande área das Ciências Sociais Aplicadas (10,86\%) e o Direito 79 (2,21\%). A representatividade do Direito (58) na grande área é de 19,93\% dos Programas (291) e de 20,36\% (79) dos Cursos (388), segundo dados fornecidos pela CAPES em 19 de setembro de 2006 . $^{17}$

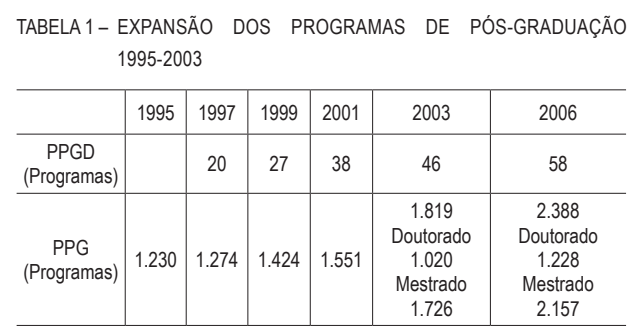

FONTE: Capes 19/9/2006

Em 2006, a Área de Direito passa a contar com 58 Programas, dos quais 37 são

17 Todos os dados fornecidos pela CAPES estão disponíveis nas estatísticas divulgadas no sítio www.capes.gov.br. 
Cursos que ofertam tão-somente Mestrado e 21 são Programas com Cursos de Mestrado e Doutorado.

TABELA2 - AVALIAÇÃO DOS CURSOS DE MESTRADO E DOUTORADO PELACAPES

\begin{tabular}{l|c|c|c|c|c}
\hline Avaliação CAPES & 3 & 4 & 5 & 6 & 7 \\
\hline Mestrado (58) & 33 & 12 & 9 & 4 & 0 \\
\hline Doutorado (21) & 1 & 8 & 8 & 4 & 0 \\
\hline
\end{tabular}

FONTE: Capes/2006

Integravam o Sistema Nacional de Pósgraduação em 2001 apenas 38 Programas, sendo 16 em instituições públicas ${ }^{18} \mathrm{e}$ gratuitas, federais ou estaduais, a saber, UFSC, UFPR, USP, UERJ, UFRGS, UFMG, UFPE, UNB, UFPB, UFPA, UFBA, UFC, UEL, UNESP, UEM e UFG (42\%) e 22 em instituições privadas, ou seja, UNISINOS, PUC/RS, PUC/RIO, PUC/MG, PUC/SP, UGF, PUC/PR, UNIMES, FEESR, ITE, FDC, FDMC, UCAM, UNAMA, UNISC, UNIVALI, UNIMEP, UCS, UPM, UNAERP, UNIFRAN e UNIG (58\%). Atualmente são 18 IES públicas (31\%) e 40 privadas $(69 \%)$; com oferta de doutorado, a distribuição é mais homogênea, sendo 11 IES privadas $(52,5 \%)$ e 10 públicas $(47,5 \%)$, embora o crescimento se verifique exatamente nas IES privadas. Neste trilhar, nos últimos 5 (cinco) anos (2001/2006) foram credenciados 19 novos cursos de mestrado com projetos apresentados por IES privadas e somente 3 (três) dentre as IES públicas.

No ano de 2002, ingressaram no SNPG os Cursos de Mestrado da UNIFOR, UNESA,

${ }^{18}$ A classificação das instituições de ensino superior em públicas (criadas ou incorporadas, mantidas e administradas pelo Poder Público) e privadas (mantidas e administradas por pessoas físicas ou jurídicas de direito privado) é indicativo presente no art. 1, do Decreto 3.860, de 9 de julho de 2001, que dispõe sobre a organização do ensino superior.
UNIPAR, FDV e UNISANTOS, totalizando então 43 Programas, com a oferta de mais 5 (cinco) cursos em instituições privadas.

No ano seguinte, ao final de 2003, a Área do Direito contabilizava 42 Programas, resultado do credenciamento de uma instituição pública, a UFRN e de outras 2 (duas) instituições privadas, a FUNDINOPI ${ }^{19}$ e a UNICEUB.

O crescimento negativo em relação ao ano anterior é devido ao resultado da avaliação trienal ocorrida em 2003, pelo descredenciamento do SNPG dos cursos de mestrado oferecidos tanto por instituição pública, no caso a UFG, quanto por outras 3 (três) instituições particulares, ou seja, UNAERP, UNIFRAN e UNIG.

Ocorre que em 2004 incorporam-se ao SNPG os cursos de Mestrado das públicas UEA e UFAL e das privadas UCB, ULBRA, UNIFIEO e UNIMAR, passando a Área do Direito a totalizar 48 Programas, sendo 30 em instituições privadas e 18 em públicas.

Mais recentemente, no ano de 2005, o SNPG absorveu 5 (cinco) novos cursos de mestrado ofertados pelas privadas UNISAL, FADISP, UNITOLEDO, FIC e CEUMAR, pelo que, dos então 53 Programas, 35 eram privados e pagos.

No corrente ano, em 2006, retorna ao SNPG a UNAERP, com novo projeto aprovado pelo CTC/CAPES, além da inclusão de outras 2 (duas) particulares, a URI e a UNICAP e também uma pública, a UFES, passando a Área do Direito a contar com 37 Programas de Pós-graduação privados dentro de um total de 58 credenciados.

\footnotetext{
${ }^{19}$ Atualmente é instituição pública.
} 
Foram aprovados 5 (cinco) novos cursos de doutorado no período, a saber, PUC-PR, ${ }^{20}$ ITE, UNIFOR, UNIMES, UNESA.

De qualquer sorte, verifica-se (tabela 3) que o crescimento do número de cursos de Mestrado e Doutorado, ano a ano, não foi linear, nem seguem uma mesma tendência, sendo por vezes até negativo, o que demonstra à saciedade que a expansão não é resultado de uma específica Política Pública ou de algum critério ou decisão da Área do Direito, quer para ampliar as públicas em detrimento das privadas - ou vice-versa -, quer para aumentar prioritariamente a oferta de cursos de Mestrado ou de Doutorado em uma específica região ou estado-membro.

TABELA 3 - EXPANSÃO DOS PROGRAMAS DE PÓS-GRADUAÇÃO EM DIREITO

\begin{tabular}{c|c|c|c|c}
\hline ANO & $\begin{array}{c}\text { Cursos de } \\
\text { Doutorado }\end{array}$ & $\begin{array}{c}\text { expansão /ano } \\
\text { (acumulado 425\%) }\end{array}$ & $\begin{array}{c}\text { Cursos de } \\
\text { Mestrado }\end{array}$ & $\begin{array}{c}\text { expansão /ano } \\
\text { (acumulado } \\
222,22 \%)\end{array}$ \\
\hline 2006 & 21 & $31,25 \%$ & 58 & $9,43 \%$ \\
\hline 2005 & 16 & $6,66 \%$ & 53 & $10,41 \%$ \\
\hline 2004 & 15 & $7,14 \%$ & 48 & $9,52 \%$ \\
\hline 2003 & 14 & $0 \%$ & 42 & $-7,69 \%$ \\
\hline 2002 & 14 & $0 \%$ & 43 & $13,2 \%$ \\
\hline 2001 & 14 & $21,4 \%$ & 38 & $2,7 \%$ \\
\hline 2000 & 11 & $0 \%$ & 37 & $37 \%$ \\
\hline 1999 & 11 & $0 \%$ & 27 & $17,4 \%$ \\
\hline 1998 & 11 & $120 \%$ & 23 & $15 \%$ \\
\hline 1997 & 5 & $25 \%$ & 20 & $11,1 \%$ \\
\hline 1996 & 4 & & 18 & \\
\hline
\end{tabular}

FONTE: CAPES 19/9/2006 *descredenciados 4 cursos de mestrado e credenciados 3 novos cursos de mestrado

Ademais, imperioso notar que o crescimento dos Cursos de Doutorado nos últimos 10 anos, embora seja mais expressivo do que o dos Mestrados, não representou a expansão numérica do aumento no número de novos doutores titulados (tabela 4), da mesma forma que o credenciamento e a expansão dos novos Cursos de Mestrado não reproduziram

${ }^{20}$ Homologado pelo CNE (Portaria n. ${ }^{\circ} 679$ - DOU 16/03/06 - Parecer 474/2005, 15/03/2006). o mesmo percentual na titulação dos mestres (tabela 5).

TABELA 4 - EXPANSÃO NOS CURSOS DE DOUTORADO 1996/2004

\begin{tabular}{c|c|c|c|c}
\hline ANO & $\begin{array}{c}\text { Cursos de } \\
\text { Doutorado }\end{array}$ & $\begin{array}{c}\text { acumulado } \\
(\%)\end{array}$ & $\begin{array}{c}\text { novos doutores } \\
\text { titulados }\end{array}$ & $\begin{array}{c}\text { crescimento } \\
\text { acumulado }\end{array}$ \\
\hline 2004 & 15 & 275 & 236 & $972,72 \%$ \\
\hline 2003 & 14 & & 243 & $1004 \%$ \\
\hline 2002 & 14 & & 165 & $650 \%$ \\
\hline 2001 & 14 & 250 & 131 & $495,45 \%$ \\
\hline 2000 & 11 & & 114 & $418,18 \%$ \\
\hline 1999 & 11 & & 79 & $259,09 \%$ \\
\hline 1998 & 11 & 175 & 53 & $140,90 \%$ \\
\hline 1997 & 5 & 25 & 21 & $-4,54 \%$ \\
\hline 1996 & 4 & & 22 & \\
\hline
\end{tabular}

FONTE: CAPES/2006

TABELA 5 - EXPANSÃO NOS CURSOS DE MESTRADO 1996/2004

\begin{tabular}{c|c|c|c|c}
\hline ANO & $\begin{array}{c}\text { Cursos de } \\
\text { Mestrado }\end{array}$ & acumulado (\%) & $\begin{array}{c}\text { novos mestres } \\
\text { titulados }\end{array}$ & acumulado (\%) \\
\hline 2004 & 48 & 166,66 & 1.526 & 698,95 \\
\hline 2003 & 46 & 155,55 & 1.797 & 840,83 \\
\hline 2002 & 43 & 138,88 & 1.508 & 689,52 \\
\hline 2001 & 38 & 111,11 & 1.093 & 472,25 \\
\hline 2000 & 37 & 105,55 & 676 & 253,92 \\
\hline 1999 & 27 & 50 & 483 & 152,87 \\
\hline 1998 & 23 & 27,77 & 291 & 52,35 \\
\hline 1997 & 20 & 7,14 & 259 & 35,6 \\
\hline 1996 & 18 & & 191 & \\
\hline
\end{tabular}

FONTE: CAPES/2006

A expansão na Área de Direito foi mais intensa do que a verificada no SNPG em relação às outras áreas, tanto em número de titulados (novos mestres e doutores) quanto em Programas (Cursos de Mestrado e Doutorado), revelando o impacto da pressão exercida pela ampliação desmesurada da graduação. Entre os anos 1996 e 2004, a Área de Direito titulou 1.064 doutores, com um crescimento de titulados/ano da ordem de $972,72 \%$, ao passo que entre 1995 e 2003 , no SNPG, o aumento de titulados/ano foi apenas de $220 \%$.

No período, o número de Programas com cursos de Doutorado em Direito cresceu menos $(275 \%)$ do que o número de titulados/ano (972,72\%). Do mesmo modo, entre 1996 e 2004, 7.824 novos Mestres em 
Direito foram titulados, o que representou um aumento de 698,95\% de titulados/ano, enquanto na pós-graduação como um todo, a expansão beirou os 198,21\%, apesar de o crescimento no mesmo período dos Cursos de Mestrado ter sido de somente $166,66 \% .^{21}$

A capacidade de absorção (tabela 6) de novos doutores no Corpo Docente dos Programas de Pós-graduação em Direito se restringe a no máximo $44,17 \%$, porquanto pelos dados meramente quantitativos disponibilizados não se tem a origem dos títulos. Certamente, com a possibilidade de obtenção de títulos em universidades estrangeiras e a conseqüente revalidação nacional, o grau de incorporação seja significativamente menor. De qualquer sorte, entre 1996 e 2004, houve um incremento no número de docentes em 141,56\% - já descontados os duplicados -, totalizando 470 novos doutores integrantes do Corpo Docente nos Programas de Pós-graduação em Direito, ${ }^{22}$ ou seja, $44,17 \%$ dos 1.064 novos doutores titulados no período.

TABELA 6 - NOVOS DOUTORES - 1997/2004

\begin{tabular}{c|c|c|c|c|c}
\hline ANO & $\begin{array}{c}\text { Programas de } \\
\text { Pós-graduação } \\
\text { em Direito }\end{array}$ & $\begin{array}{c}\text { Docentes } \\
\text { doutores }\end{array}$ & $\begin{array}{c}\text { crescimento } \\
\text { acumulado }\end{array}$ & $\begin{array}{c}\text { Novos } \\
\text { doutores } \\
\text { titulados/ano }\end{array}$ & $\begin{array}{c}\text { crescimento } \\
\text { acumulado }\end{array}$ \\
\hline 2004 & 48 & 802 & $141,56 \%$ & 236 & $972,72 \%$ \\
\hline 2003 & 46 & 829 & $149,69 \%$ & 243 & $1004 \%$ \\
\hline 2002 & 43 & 704 & $112,04 \%$ & 165 & $650 \%$ \\
\hline 2001 & 38 & 614 & $84,93 \%$ & 131 & $495,45 \%$ \\
\hline 2000 & 37 & 580 & $74,69 \%$ & 114 & $418,18 \%$ \\
\hline 1999 & 27 & 497 & $49,69 \%$ & 79 & $259,09 \%$ \\
\hline 1998 & 23 & 443 & $33,43 \%$ & 53 & $140,90 \%$ \\
\hline 1997 & 20 & 402 & $21,08 \%$ & 21 & $-4,54 \%$ \\
\hline 1996 & 18 & 332 & & 22 & \\
\hline
\end{tabular}

FONTE: CAPES/2006

${ }^{21}$ Dados obtidos nas estatísticas da pós-graduação disponibilizadas pela CAPES através do site http:// www.capes.gov.br ; acesso em 17 de março de 2006.

${ }^{22}$ Muitos Programas informaram a presença de docentes não doutores, que foram descartados quantitativamente, embora possa advir de erro no preenchimento.
A se tomar em consideração que a Área do Direito estabeleceu como critério para apresentação de novos projetos de Cursos de Mestrado a presença de pelo menos 10 (dez) doutores em Direito no Corpo Docente Permanente e, ainda, diante do escopo da pósgraduação que é preparar novos docentes e (ou) pesquisadores, o SNPG poderia absorver como resultado desse excedente de titulados entre 1996 a 2004, a saber, 594 doutores, ou seja, com um potencial de credenciamento de pelo menos 59 novos pedidos.

Interessante observar que ao tempo do credenciamento de 30 novos Programas de Pós-graduação no mesmo período, a média de acréscimo de docentes foi da ordem de 15,6 doutores por curso, ou seja, mais do que a própria Área de Direito estabeleceu como critério mínimo.

De qualquer sorte, em apertada síntese, conclui-se que há uma expansão na Área do Direito mais impactante do que o próprio crescimento da Pós-graduação, embora a absorção de novos doutores pela própria Pósgraduação seja menos da metade dos titulados, o que requer alguma atenção diante da pressão dos cursos de graduação para atingirem a meta estabelecida pela Lei de Diretrizes e Bases da Educação quanto ao percentual de 1/3 de professores titulados mestres ou doutores ${ }^{23}$ ministrando aulas na graduação.

\section{O IMPACTO DAS POLÍTICAS PÚBLICAS: BOLSAS E FOMENTO}

A Pós-graduação não tem como único escopo a formação de docentes ou a qualificação de mão-de-obra para o mercado

${ }^{23}$ Art. 52, inciso II, da Lei n. ${ }^{\circ} 9.394$, de 20 de dezembro de 1996. Lei de Diretrizes e Bases da Educação-LDB. 
de trabalho por meio da concessão de um grau acadêmico, porém visa, sobretudo, ao desenvolvimento da pesquisa científica, contando para tanto com os recursos das agências de fomento públicas federais e estaduais, assim como também com o financiamento próprio das instituições. Não há pesquisa sem financiamento.

Para que se possa traçar o perfil da pesquisa no Brasil optou-se, então, pela análise dos dados levantados junto ao $\mathrm{CNPq},{ }^{24}$ que tem o grande mérito de permitir a realização de um censo mediante a Plataforma Lattes, por meio do curriculum vitae dos pesquisadores e grupos de pesquisa no Brasil, assegurando a publicidade e a transparência necessária para a análise da produção científica. Outrossim, o curriculum lattes dos proponentes tem sido um dos parâmetros adotados para análise de mérito nos pedidos de concessão de bolsas e para (in)deferimento de pedidos de financiamento da pesquisa, por meio da verificação da produção intelectual.

O número de doutores por habitante e o investimento per capita em pesquisa revelam-se ainda inexpressivos no Brasil, em conformidade com os dados fornecidos pelo CNPq (tabelas 7 e 9), chegando a uma média no Brasil, no ano de 2004, equivalente ao montante de $\mathrm{R} \$ 4,5$ por pessoa, apesar de ter apresentado no curso dos anos 2000 a 2004 um incremento no aporte financeiro global; houve uma ampliação dos recursos disponíveis no período para bolsas e fomento de 75,66\% quando em igual período o número de Programas de Pós-graduação em Direito tiveram uma expansão de $29,72 \%$.

24 Disponível no site <http://www.cnpq.br>, acessado em 17 de março de 2003.
Mister salientar, no entanto, que os investimentos estão concentrados ainda nas Regiões Sudeste, Sul e Centro-Oeste, ao passo que nas demais regiões (Norte e Nordeste), somados os recursos, resultam inferiores a $50 \%$ da média nacional.

TABELA 7 (EM R\$ 1,00) - INVESTIMENTO PER CAPITA

\begin{tabular}{l|c|c|c}
\hline \multicolumn{1}{c|}{ REGIÃO / ESTADO } & 2000 & 2002 & 2004 \\
\hline NORTE & $\mathbf{0 , 7}$ & $\mathbf{1 , 0}$ & $\mathbf{2 , 1}$ \\
\hline AMAZONAS & 2,1 & 1,4 & 3,4 \\
\hline PARÁ & 0,8 & 1,2 & 2,2 \\
\hline NORDESTE & $\mathbf{1 , 3}$ & $\mathbf{1 , 3}$ & $\mathbf{2 , 2}$ \\
\hline BAHIA & 0,8 & 0,9 & 1,7 \\
\hline PERNAMBUCO & 2,3 & 2,4 & 3,8 \\
\hline SUDESTE & $\mathbf{3 , 5}$ & $\mathbf{3 , 8}$ & $\mathbf{5 , 5}$ \\
\hline RIO DE JANEIRO & 6,0 & 6,4 & 8,9 \\
\hline SÃO PAULO & 3,4 & 3,5 & 5,4 \\
\hline SUL & $\mathbf{2 , 8}$ & $\mathbf{3 , 5}$ & $\mathbf{4 , 8}$ \\
\hline PARANÁ & 1,5 & 1,9 & 2,6 \\
\hline RIO GRANDE DO SUL & 3,9 & 4,8 & 6,8 \\
\hline CENTRO-OESTE & $\mathbf{2 , 4}$ & $\mathbf{3 , 0}$ & $\mathbf{4 , 2}$ \\
\hline DISTRITO FEDERAL & 10,2 & 14,1 & 16,3 \\
\hline GOIÁS & 0,8 & 0,6 & 1,2 \\
\hline BRASIL & $\mathbf{2 , 9}$ & $\mathbf{3 , 6}$ & $\mathbf{4 , 5}$ \\
\hline
\end{tabular}

FONTE: CNPq/BGG/2006

Os demais dados demonstram que paulatinamente a desigualdade regional verificada nas Regiões Norte e Nordeste está sendo reduzida, com o crescimento do número de doutores e da relação doutores/habitante, embora ainda demande políticas públicas que priorizem a superação da diversidade. O número de doutores por região (tabela 8) e por habitante (tabela 9) entre 2000 e 2004, alargou em 143,97\% na Região Norte e em 96,86\% na Região Nordeste.

Aliás, conclui Paulo Sérgio Marchelli, em estudo comparativo da formação de doutores nos cursos de pós-graduação brasileiros e de outros países (EUA, França, Alemanha, Reino Unido, Japão e Coréia do 
Sul), com a demonstração de um significativo crescimento relativo do número de doutores por cem mil habitantes na última década com formação no Brasil. Indica o autor que até 1985 mais de $40 \%$ dos doutores obtinham o grau acadêmico em instituições estrangeiras, situação que se reverte com uma política de expansão especialmente na década de 1990, com crescimento no número de matrículas de 11.952 para 33.044 alunos (176\%) distribuídos em 864 cursos, resultando em um aumento de $68 \%$ em relação aos 503 integrantes do SNPG. ${ }^{25}$

Tal situação, no entanto, não ocorre especificamente no Direito, em que se verifica exatamente o inverso, ou seja, a ampliação do número de bolsas concedidas para estudos no exterior, apesar de ser uma peculiaridade da Área exatamente o recorte nacional do conhecimento científico.

TABELA 8 - DOUTORES POR REGIÃO

\begin{tabular}{l|c|c|c}
\hline \multicolumn{1}{c|}{ REGIÃO / ESTADO } & 2000 & 2002 & 2004 \\
\hline NORTE & 705 & 1.152 & 1.721 \\
\hline AMAZONAS & 270 & 433 & 652 \\
\hline PARÁ & 339 & 543 & 733 \\
\hline NORDESTE & 3.705 & 5.168 & 7.294 \\
\hline BAHIA & 740 & 1.070 & 1.803 \\
\hline PERNAMBUCO & 1.143 & 1.377 & 1.812 \\
\hline SUDESTE & 17.354 & 20.540 & 28.837 \\
\hline RIO DE JANEIRO & 4.553 & 5.206 & 7.597 \\
\hline SÃO PAULO & 10.187 & 12.177 & 16.955 \\
\hline SUL & 5.034 & 7.165 & 10.312 \\
\hline PARANÁ & 1.695 & 2.435 & 3.662 \\
\hline RIO GRANDE DO SUL & 2.497 & 3.414 & 4.730 \\
\hline CENTRO-OESTE & 1.873 & 2.404 & 3.632 \\
\hline DISTRITO FEDERAL & 1.048 & 1.199 & 1.729 \\
\hline GOIÁS & 487 & 656 & 969 \\
\hline
\end{tabular}

FONTE: CNPq/Grupos de Pesquisa//BGE/2006

${ }_{25}$ MARCHELLI, Paulo Sérgio. Formação de doutores no Brasil e no mundo: algumas comparações. RBPG, Brasília, mar.05,v.2, n.3, p.9.
TABELA 9 - DOUTORES POR HABITANTE (POR 100 MIL HABITANTES)

\begin{tabular}{l|c|c|c|c|c}
\hline REGIÃO / ESTADO & 2000 & 2002 & 2004 & $2000 / 2004$ & $2000 / 2004$ \\
\hline NORTE & 5,4 & 8,4 & 12,0 & $122,22 \%$ & \\
\hline AMAZONAS & 9,5 & 14,4 & 20,6 & & $116,84 \%$ \\
\hline PARÁ & 5,4 & 8,3 & 10,7 & & $98,14 \%$ \\
\hline NORDESTE & 7,7 & 10,5 & 14,5 & $88,31 \%$ & \\
\hline BAHIA & 5,6 & 8,0 & 13,2 & & $135,71 \%$ \\
\hline PERNAMBUCO & 14,3 & 16,9 & 21,8 & & $52,44 \%$ \\
\hline SUDESTE & 23,8 & 27,3 & 37,3 & $58,69 \%$ & \\
\hline RIO DE JANEIRO & 31,4 & 35,1 & 50,0 & & $59,23 \%$ \\
\hline SÃO PAULO & 27,2 & 31,6 & 42,6 & & $56,61 \%$ \\
\hline SUL & 19,9 & 27,6 & 38,7 & $94,47 \%$ & \\
\hline PARANÁ & 17,6 & 24,6 & 36,1 & & $105,11 \%$ \\
\hline RIO GRANDE DO SUL & 24,3 & 32,5 & 44,1 & & $81,48 \%$ \\
\hline CENTRO-OESTE & 15,9 & 19,6 & 28,4 & $78,61 \%$ & \\
\hline DISTRITO FEDERAL & 50,4 & 55,0 & 75,8 & & $50,39 \%$ \\
\hline GOIÁS & 9,6 & 12,4 & 17,6 & & $83,33 \%$ \\
\hline BRASIL & 16,2 & 19,5 & 26,4 & $62,96 \%$ & \\
\hline
\end{tabular}

FONTE: CNPq/Grupos de Pesquisa//BGE/2006

$\mathrm{Na}$ distribuição dos recursos repassados pelo $\mathrm{CNPq}$ para pagamento de bolsas no exterior, relativo ao período compreendido entre 1999 e 2004, comprova-se um crescimento de $223,21 \%$, por sinal em muito superior ao das outras áreas (40,37\%), ao passo que as bolsas concedidas no país aumentaram somente $19,12 \%$ (tabelas 10 e 11). A se levar em conta o crescimento do número de titulados nos Programas de Pósgraduação em Direito entre 2000 e 2004 e que poderiam se beneficiar dos recursos disponíveis para bolsas, a expansão da concessão das bolsas foi muito inferior ao dos titulados no Doutorado e no Mestrado, respectivamente $107,01 \%$ e $125,73 \%$ (tabelas 5 e 6$)$.

TABELA 10 (EM R\$ MIL) - BOLSAS NO EXTERIOR

\begin{tabular}{l|c|c|c|c|c|c|c}
\hline \multicolumn{1}{c|}{ ANO } & 1999 & 2000 & 2001 & 2002 & 2003 & 2004 & $\begin{array}{c}\text { expansão } \\
1999 / 2004\end{array}$ \\
\hline $\begin{array}{l}\text { TODAS } \\
\text { ÁREAS }\end{array}$ & 26.514 & 24.133 & 43.100 & 56.643 & 40.258 & 37.219 & $40,37 \%$ \\
\hline DIREITO & 112 & 67 & 153 & 444 & 231 & 362 & $223,21 \%$ \\
\hline
\end{tabular}

FONTE: CNPq/2006

TABELA 11 (EM R\$ MIL) - BOLSAS CNPQ NO PAÍS

\begin{tabular}{l|c|c|c|c|c|c|c}
\hline ANO & 1999 & 2000 & 2001 & 2002 & 2003 & 2004 & $\begin{array}{c}\text { expansão } \\
1999 / 2004\end{array}$ \\
\hline TODAS & 306.783 & 318.568 & 338.590 & 341.462 & 393.328 & 490.378 & $59,84 \%$ \\
ÁREAS & 2.160 & 2.107 & 2.170 & 1.963 & 2.144 & 2.573 & $19,12 \%$ \\
\hline DIREITO & 2.160 \\
\hline
\end{tabular}


A pouca expressividade que o CNPq tem na Área do Direito é comprovada (a) pela situação do Direito no ranking das Áreas na alocação dos recursos, pois dentre as 74 que se beneficiam de investimentos o Direito ocupa tão-somente o $55^{\circ}$ lugar e (b) pelo número de bolsistas pesquisadores em produtividade (tabela 12), que totalizam 30 em todo o país. Os bolsistas de produtividade em pesquisa, prioritariamente realizam suas atividades em instituições da Região Sul (1/3) e quase metade na Região Sudeste, com predominância de pesquisadores de instituições públicas (70\%). $\mathrm{Na}$ Área de Ciências Sociais Aplicadas as bolsas de produtividade em pesquisa fornecidas pelo $\mathrm{CNPq}$ traduzem um número consideravelmente elevado, atingindo atualmente 517 pesquisadores.

TABELA 12 - BOLSISTA DE PRODUTIVIDADE POR REGIÃO

\begin{tabular}{l|c|c}
\hline \multicolumn{1}{c|}{ INSTITUIÇÃO/REGIÃO (BOLSISTA) } & REGIÃO & $\%$ \\
\hline SUL & 10 & $33,33 \%$ \\
\hline UFRGS(1) UFPR(1) UFSC(3) PUCRS (2) UNISINOS (3) & & \\
\hline SUDESTE & 14 & $46,6 \%$ \\
\hline UNESP(1) UNIRIO(1) PUCRJ (1) UFRJ(2) USP (2) & & \\
\hline UERJ (3) UFMG (3) UFG (1) & 2 & $6,66 \%$ \\
\hline NORDESTE & & \\
\hline UFAL(1) UFPE (1) & 3 & $10 \%$ \\
\hline CENTRO-OESTE & & \\
\hline UNB (2) UNICEUB(1) & 1 & $3,33 \%$ \\
\hline NORTE & & \\
\hline UFPA(1) & 30 & $100 \%$ \\
\hline TOTAL DIREITO & 517 & $5,20 \%$ \\
\hline TOTAL CIÊNCIAS SOCIAIS APLICADAS
\end{tabular}

FONTE: CNPq/2006 * dados de novembro de 2006 **dados do início de 2006

Apesar da expansão identificada na Área do Direito e do incremento das pesquisas, há uma sub-representação em relação aos investimentos destinados ao fomento à pesquisa (tabela 13) que podem revelar (a) desconhecimento das linhas abertas pelas agências de fomento; ou (b) rechaço ao preenchimento de formulários e relatórios, bem como prestação de contas; ou, ainda, (c) identificação da pesquisa como espaço de atuação individual, não formalizada institucionalmente e mediante levantamento bibliográfico recapitulativo, o que diminui a necessidade de aportes financeiros, pois independe de material de consumo específico ou instrumentos a serem adquiridos. Há mudança positiva decorrente dos critérios de avaliação e requisitos para apresentação de projetos para cursos novos, mediante comprovação de linhas de pesquisa e grupos consolidados na instituição de ensino superior, identificada no sentido do aumento do número de grupos de pesquisa no $\mathrm{CNPq}$.

Positivo, ainda, o viés interdisciplinar da pesquisa e docência nos Programas de Pós-graduação, com inserção social, abrindo espaços para pesquisa de campo. Direito, afinal, não se restringe, nem pode limitar-se ao estudo da legislação.

TABELA 13 (EM R\$ MIL) - FOMENTO À PESQUISA

\begin{tabular}{l|c|c|c|c|c|c|c}
\hline ANO & 1999 & 2000 & 2001 & 2002 & 2003 & 2004 & $\begin{array}{c}\text { expansão } \\
1999 / 2004\end{array}$ \\
\hline TODAS & 48.728 & 94.372 & 135.824 & 107.438 & 117.131 & 173.742 & $48,33 \%$ \\
ÁREAS & 14 & 92 & 29 & 170 & 154 & 598 & $288,10 \%$ \\
\hline DIREITO & 14 \\
\hline
\end{tabular}

Dentre os Editais e Programas existentes na CAPES, destacam-se:

- Escola de Altos Estudos;

- Programa Institucional de Capacitação de Docentes no ensino tecnológico;

- Programa de apoio a eventos científicos PAEP;

- Programa de qualificação institucional PQI;

- Programa de suporte à pós-graduação de instituições de ensino particulares PROSUP;

- Programa de fomento à pós-graduação PROF; 
- Programa de excelência acadêmica PROEX;

- Programa de demanda social - DS;

- Programa nacional de cooperação acadêmica - PROCAD;

- Programa de apoio à pesquisa em educação à distância - PAPED;

- Cooperação internacional (CAPES/ GRICES; CAPES/CONEAU; CAPES/ COFECUB e outros);

- Programa de professor visitante estrangeiro - PVE;

- Programa PEC-PG - estudantes estrangeiros;

- Bolsas:

$\sqrt{ }$ doutorado sanduíche;

$\checkmark$ recém-doutor;

$\sqrt{ }$ Mestrado;

$\sqrt{ }$ Doutorado;

$\sqrt{ }$ Pós-doutorado no país e no exterior;

- Mestrado Interinstitucional - MINTER; e

- Doutorado Interinstitucional - DINTER.

No CNPq, destacam-se:

- Bolsas individuais no país:

$\sqrt{ }$ Produtividade em pesquisa;

$\sqrt{ }$ Produtividade em desenvolvimento tecnológico e extensão inovadora;

$\sqrt{ }$ Pesquisador visitante;

$\sqrt{ }$ Pesquisador visitante especial;

$\sqrt{ }$ Iniciação científica júnior;

$\sqrt{ }$ Desenvolvimento científico regional;

$\sqrt{ }$ Pós-Doutorado Júnior e Sênior;

$\sqrt{ }$ Doutorado-sanduíche no país;

$\sqrt{ }$ Pós-Doutorado empresarial;

$\sqrt{ }$ Doutorado sanduíche empresarial;

- Auxílios; $\sqrt{ }$ Auxílios de curta duração;

- Pesquisador Visitante;

- Participação em eventos científicos;

- Promoção de eventos científicos;

$\sqrt{ }$ Projetos individuais de Pesquisa;

- Projeto de Pesquisa;

$\sqrt{ }$ Programa de apoio às publicações científicas;

- Bolsas por quota ao Curso;

$\sqrt{ }$ Doutorado;

$\sqrt{ }$ Mestrado;

$\sqrt{ }$ Pós-graduação integrada (doutorado direto);

- Bolsas por quota ao pesquisador;

$\sqrt{ }$ Apoio técnico.

\section{À GUISA DE CONCLUSÃO}

A pós-graduação brasileira vem sofrendo o impacto da expansão da graduação que atingiu o patamar de mais de mil cursos de Direito em funcionamento no Brasil em 4 de agosto de $2006,{ }^{26}$ mas a demanda revelada pelo crescimento das bolsas concedida por instituições de fomento para realização de

${ }^{26}$ Os advogados inscritos nas respectivas seções da OAB totalizavam naquela data a marca de 517 mil. Nos EUA seriam apenas 205 os cursos de direito oferecidos, sendo que na Califórnia, seu estado mais populoso, estão funcionando 23 cursos, ao passo que em São Paulo atingiu-se a quantia de 222 em agosto de 2006. Levantamento de dados realizado e divulgado pela Comissão de Ensino Jurídico do Conselho Federal da OAB. Na avaliação do Presidente do Conselho Federal da OAB, "não há condições da manutenção de uma advocacia organizada no país com essa quantidade de advogados. Não pelo seu número, mas pela sua má formação, pela má qualidade do ensino que os bacharéis em Direito vêm recebendo." Disponível a notícia no sítio <http://aprendiz.uol.com.br>, acessado em 09 de agosto de 2006. 
doutorado no exterior indica a possibilidade de absorção de novos cursos, principalmente de doutorado.

As políticas públicas estabelecidas pela CAPES nas últimas décadas, primando pela qualidade dos cursos de pós-graduação em detrimento da quantidade, até o momento preservam o sistema nacional de pósgraduação da pressão pela mercantilização da educação verificada na graduação.
Odesembolso para fomento, financiamento da pesquisa e bolsas é ainda exíguo diante do número de doutores titulados e irrelevante como investimento em ciência em relação ao contingente populacional, merecendo da parte do Estado maior prioridade, demonstrando que a execução de políticas públicas para a Área de Direito na Capes e no CNPq não vem tendo uma trajetória uniforme e coordenada. 
